\title{
Analyzing the country events registration of the safe community project using E \& CFA technique: Case study of Esfahan Province
}

\author{
Hamzeh Zarei1 ${ }^{1}$, Saeed Givehchi ${ }^{2}$, Mahanaz Nasrabadi ${ }^{3}$
}

Received: 20.08.2015

Revised: 25.09 .2015

Accepted: 30.11.2015

\begin{abstract}
The present study aims to analyze the events of the safe community project of Esfahan using E \& CFA technique. Safe community project includes the initial preparations for the establishment of a safety culture in societies and providing purposeful management solutions to prevent the occurrence of various events. With the aggregate of the statistics on a variety of accidents with clear definitions, a good statistical population to be examined and analyzed is created. The statistical sample in this study consists of all the victims of the events recorded in the software relating to the state safe community project and in the section about the investigation of accidents by questionnaire, technical experts in the staff units of Health Center No. 1 in Esfahan analyzed the two selected events in the form of responding to components associated with intermediate and root causes and provided preventive and control measures. The instruments applied in this research included a questionnaire on the analysis of intermediate and root causes and a questionnaire concerning the assessment of preventive and control measures. Also, the degree of importance of each component and its relationship with other components were evaluated using Kruskal-Wallis test and then, the intended components were ranked. Further, brainstorming sessions were held with the presence of 5 technical experts and 5-why tool and Ishikawa root cause diagram were used as a tool for investigating causal relationships in the two selected events. The test results indicated that each component in the questionnaire is not associated with other components and can be effective alone in creating the desired effect.
\end{abstract}

\section{Introduction}

Although Humanities evolution from the hunting era to the age of Industrial Revolution led to increased enjoyment of humans from natural resources, from another dimension, it made them confronted with new problems since humans began to discover and invent new devices and apply newer technologies to meet their needs in their growing trend. All of these efforts led to a rapid increase and acceleration in making desired changes. But these developments, in addition to positive effects, have equally led to negative effects because these changes were followed by unforeseen factors that caused the incidence of injury, damage and various losses (Haji Hoseini, 2010: 3). A comparison of major events in various countries, apart from the level of their developedness, indicates their great similarities with each other. Factors such as human errors, too much confidence in the safety of facilities, problems in designing, lack of preparation in critical situations and non-compliance with HSE standards in technology transfer (in less developed countries) have been among the main reasons for the incidence of human and enviro-

\footnotetext{
Author's Address

${ }^{1}$ Department of Environment Management (HSE), Faculty of Engineering and Technology, Islamic Azad University, Zahedan Branch, Zahedan, Iran

${ }^{2}$ Department of Environment,Tehran University, Iran,

3 Department of Environment Management (HSE), Faculty of Engineering and Technology, Islamic Azad University, Zahedan Branch, Zahedan, Iran

Email: Givehchi1@gmail.com
}

nmental disasters. All of the factors mentioned above are present in our country, which have led to the occurrence of major accidents (Mearnd et al., 2001). With increasing the speed of science developments and introducing new materials and technologies, newer problems arise at any moment in workplaces and performance of different organizations and certainly dealing with them and controlling their unacceptable risks require knowledge of new approaches, methods and techniques in the realm of safety science (Mohammadfam, 2009).

Today, the use of risk assessment methods in different industries and organizations is growing so that currently, more than 100 different types of qualitative and quantitative risk assessment methods exist in the world. These methods which are usually applied to identify, control and reduce the consequences of hazards are major and appropriate methods to assess the risks and their results can be used without worry to manage and make decisions about controlling and reducing their outcomes. Each of the organizations or industries, depending on their needs, can benefit from the aforesaid methods. These methods have various advantages and disadvantages relative to each other. Thus, one of the tasks of health and safety systems existing in any organization or industry (HSE) is to examine all risk assessment methods and select an appropriate method for implementation in its 


\section{Zarei1 et al}

respective industry and organization. Generally, it can be said that from the method used in risk assessment and depth of its evaluation, we can partially gain some knowledge about the ability of the existing immune system and hence the manner of safety management in the mentioned industry or organization (HSE engineering website, 2013).

In the world, over 5 million people die each year as a result of the damage caused by accidents, which account for one-tenth of all deaths and tens of millions people refer to emergency medical centers because of unintentional accidents such as road accidents, drowning, falling, burning and poisoning or intentional events like murder, suicide, war and aggression. In Iran, injuries are the second leading cause of death in all age groups and the first cause of death in the age group under 40 years. In the healthcare system of Iran, the state program of events registration in safe communities is operating under the supervision of the Center for Disease Control and department of state accidents and assumes the important task of storing and analyzing these events (Gelen, 1994).

Addressing the important issue of accidents and injuries under the valuable data of country events registration of the safe community can provide useful information to evaluate the main causes and the causal chain of some of these events. It is also an attempt to advance the objectives of the prospect of 1404 and consequently the fifth five-year plan of the Islamic Republic of Iran.

This study seeks to identify and assess the accidents of country events registration of the safe community in Esfahan Province with an emphasis on risk assessment through Event and Casual Factor Analysis (E\&CFA).

\section{Stating the basis of the study}

According to the World Health Organization, $90 \%$ of deaths caused by accidents occur in poor countries and $50 \%$ of deaths resulting from accidents in the world are related to the age group 15-44 years. More than half of all deaths from intentional and unintentional accidents in our country pertain to road accidents, which the rate of their annual increase is equal to $10 \%$ to
$15 \%$. In economic terms, tens of billions of dollars are the cost for surgical operations, prolonged hospitalization of patients, long-term disability, rape, injuries and loss of the useful period of victims' life. Non-availability of accurate statistics and information about accidents and lack of optimal use of the existing statistics have caused that clear and effective strategies and guidelines are not applied for the prevention and care of accidents, deaths and resulting disabilities and the situation gets worse day by day. This issue is most obvious in poor and developing countries. In Iran, the highest burden of disease is allocated to the accidents under the age of 40 years (Richard et al., 2008).

Every day thousands of people are injured or killed in the accidents, including children who go to school, men and women who go to work, people who drive in the streets and people who walk in the pavements. While considering types of possible or occurred accidents in human society, safe community project intends to present an analysis concerning the causes of the occurrence of these events, in addition to providing valuable statistics regarding the description of information about events. These efforts can ultimately advance towards explaining a safety culture at the level of human society and popularize this important issue among people.

\section{Research hypotheses}

1- The most important direct cause in accidents with regard to the program of country events registration in Esfahan is the failure to adhere to the safety principles of the safe community project.

2- The most important intermediate cause in accidents with regard to the program of country events registration in Esfahan includes recklessness and incidence of human errors and negligence in the application of safety principles.

3 - The most important root cause in accidents with regard to the program of country events registration in Esfahan includes the lack of proper training and the failure to adhere to the safety principles of the safe community project.

\section{4- Conceptual model of the research}


Drawing a diagram of E \& CFA and reaching a conclusion

Determining the direct intermediate and root causes of events and drawing a chart

Applying SPSS software to analyze the data of questionnaires

Distributing the questionnaire on finding the causes of events among the personnel in charge of various health programs

Holding expert meetings for finding the causes of events using 5-why tool and Ishikawa brainstorming

Selecting two events leading to death during the years 2009-2013 based on the events intended by

Investigating the events of the safe community project for each of 13 accidents recorded in the program software

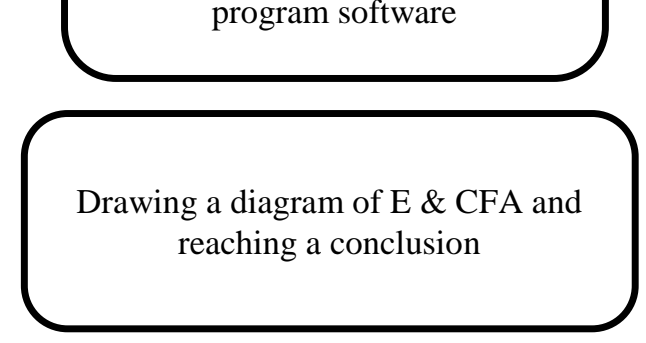

Library studies and reviewing the articles of risk assessment

Studying and applying the articles that have used methods of root cause-finding

Translation of the text related to the manual of $\mathrm{E} \& \mathrm{CFA}$ method

Receiving the software of the safe community project of Esfahan from Provincial Health Department

Extracting 5-year data of the safe community project

Using descriptive statistics for epidemiological study of the 5year data of the safe community project

Studying the articles related to the events of the safe community project based on the program of country events registration

Library studies and reviewing the articles of risk assessment

Figure 1: Method of data collection and its analysis through risk analysis technique of $E$ \& $C F A$ (Source: author); the role of human factors in the occurrence of accidents 
The main purpose of using $E \& C F A$ in analyzing the events of the safe community project of Esfahan Province

The main purpose of accident investigation by this method in relation to the events recorded in the country software of the safe community project is to examine the accidents occurred in a 5-year period (2009 to 2013) and determine what has happened and why and also recommend the necessary corrective measures in order to prevent similar and subsequent accidents and improve the safety and efficiency of performance. Therefore, the aim of investigating the accident is not to identify the guilty person, but the purpose is to determine how to clarify the responsibilities and reduce and control the catastrophic errors. Additionally, other objectives can be summarized as follows:

- Developing a cause-oriented interpretation from the accident

- Establishing appropriate changes to prevent subsequent accidents in the workplace in line with the purpose of workers' health and continuous improvement and a day without accident

- $\quad$ Providing the advantage of using E \& CFA method to assess the authenticity of potential offers

- $\quad$ Providing a method to identify the issues that need more inspection and analysis. Also, events that have been blocked with ambiguous causal factors can be considered as a warning to the inspector in order to further examine and discover the facts.

- $\quad$ And finally, applying a causal method in identifying the real causes of accidents in the great project of safe community which can provide a good result for cause-finding if accompanied by epidemiological methods.

\section{Research methodology}

Since in this article, we deal with the description and study of what exists, it is considered a descriptive research. Also, because each incident resulting in death was investigated in terms of various causes and different methods were employed for its analysis, it can be mentioned that this study is a descriptive-analytical survey which ultimately explores the various causes of the occurrence of each accident resulting in death and performs its analysis using fishbone method and root cause analysis (RCA) and finally, it is concluded with the causal diagram of E \& CFA method.

In the present study, the assessment tool is a questionnaire which is one of the common research tools and a direct method to obtain the research data. The above-mentioned questionnaire consists of four parts. In this research, the purpose of data collection through questionnaire in Health Centre No. 1 in Esfahan and the need for the cooperation of respondents in presenting the required data have been stated. To this end, the importance of causal methods especially the current method in the study has been explained and the experts in the staff units of Health Center were asked to cooperate in this regard.

Items of the questionnaire are related to the research hypotheses and according to the event described, direct, intermediate and root causes in addition to the mentioned control methods have been designed. In the design of this part, attempts have been made for the items of the questionnaire to be understandable as much as possible. These questions were initially evaluated by holding meetings with three to four individuals from the specialized committee of experts. Further, using the common tool in Ishikawa causal analysis and brainstorming technique in the intended meeting, the items in question were already set and collected for each accident and each scenario.

\section{Reliability of the questionnaire}

Reliability of this questionnaire was obtained 764.0 by Tahmasbi (2013) using Cronbach's alpha, which is considered as an acceptable measure for the questionnaire. Thus, in this study, Cronbach's alpha was calculated for each accident using Cronbach's alpha for the questionnaire.

\section{Research statistical population \\ Spatial statistical population}

This study was conducted in Health Centre No. 1 in Esfahan while taking advantage of the constructive comments of staff experts. The relevant questionnaires were distributed among the technical experts of each staff unit. Before that, meetings of 4 to 5 people were held for brainstorming and accumulation of the causes for various events.

\section{Topical statistical population}


13 accidents occurred in Isfahan Province were considered in the form of events recordable in the country software of event registration of the safe community. These statistics were separately recorded in the event software, which is in the form of Access, in two universities of Medical Sciences in the province including Esfahan University of Medical Sciences with 19 subsidiary towns (Ardestan, Esfahan town, Barkhar and Meymeh, Tiran and Kron, Chadegan, Khomeini Shahr, Khansar, Dehaqan, Semirom, Shahreza, Frieden, Fereydunshahr, Falarujan, Golpayegan, Lenjan, Mobarakeh, Naein, Najaf Abad and Natanz) and Kashan University of Medical Sciences with two towns (Kashan town and Aran and Bidgol). Finally, the statistics were sent to Ministry of Health and the relevant department in the ministry. Analysis of these statistics provided the opportunity to better review the main causes of accidents occurred. Consequently, topical statistical population of this research in the first place was for the estimation of descriptive statistics including all
13 accidents in addition to other events with various causes. Then, the events that led to death during 5 years (2009 to 2013) were analyzed selectively and based on the importance of the issue.

\section{Individual statistical population}

This population comprised all the headquarter experts of Health Center No. 1 in Esfahan. In each accident, the questionnaires were professionally distributed among them who included Bachelors, Masters and Doctors in terms of education. In Table 1, list of all the technical experts in the staff units, who helped in the field of survey and holding the professional meetings of events, has been provided. It should be noted that in each accident, the statistical population of the study was different according to the expertise of each expert and in some accidents, the number of professional experts was more than 23 and less than 30 and in some other, this number was less than 20 and more than 10 .

Table 1: List of the technical experts in different staff units of Health Center No. 1 in Esfahan (individual statistical population to complete the questionnaires and hold the meetings for specialized study of events

\begin{tabular}{|l|l|l|l|l|}
\hline No. & Academic degree & Male & Female & Total \\
\hline 1 & General practitioner & 5 & 4 & 9 \\
\hline 2 & Master & 19 & 11 & 30 \\
\hline 3 & Bachelor & 8 & 17 & 25 \\
\hline Total & & 32 & 32 & 64 \\
\hline
\end{tabular}

\section{Statistical analysis methods}

In the section of inferential statistics, statistical tests were performed using SPSS version 18 and in the section of qualitative analysis, using the data obtained from examining the statistics recorded in the software of country events registration of the safe community project, 13 events leading to death were selected, which existed in different groups of events in this project. Also, the stage of qualitative study was conducted using the checklist of $\mathrm{E} \& \mathrm{CFA}$ method including the required designed tables which were obtained from the handbook of the causal method.

\section{Sampling method and sample volume}

(If possible) the method of sampling from the individual statistical population was purposeful and based on the expertise of each expert. Sampling method of the events was selectively and based on the importance of the event and its final result and also specifications set forth in (18-12-3).

\section{Results}

In this research, Cronbach's alpha test was applied to measure the questionnaire reliability. This method is used to calculate the internal consistency of the measurement tool. In the present study, after distributing the questionnaires among the experts and collecting them, Cronbach's alpha reliability coefficient of the questionnaire was calculated using SPSS software.

Afterwards, Kruskal-Wallis test was applied to investigate the variables of the questionnaire on the animal attack on the farmer and determine the normality or abnormality of the distribution of subjects. 
7-1 Investigating the report of the events recorded in the event registration software:
Animals attack (attack of a rabid dog on a working farmer)

\section{7-1-1 Drawing the Ishikawa diagram}

Table 2: The main factors associated with the accident and descriptions of each by different instruments of Fishbone or Ishikawa method regarding the event of the animal bite of the farm

\begin{tabular}{|l|l|}
\hline $\begin{array}{l}\text { Main factors associated with } \\
\text { the accident }\end{array}$ & Descriptions \\
\hline Environment & $\begin{array}{l}\text { Environmental risks of animals attack around the farm in the early } \\
\text { hours of the day }\end{array}$ \\
\hline Humans & $\begin{array}{l}\text { The injured person's unawareness of animals attack and } \\
\text { inattentiveness to surroundings }\end{array}$ \\
\hline Primary materials & $\begin{array}{l}\text { Lack of anti-rabies vaccine in the House of Health, Health Center } \\
\text { and the selected hospital }\end{array}$ \\
\hline Methods or skills & $\begin{array}{l}\text { Wound dressing of the injured by the health worker, suturing the } \\
\text { wound by the nurse and cosmetic surgery by specialist doctors }\end{array}$ \\
\hline Policy or system & $\begin{array}{l}\text { Policy of non-distribution of vaccine in health centers and hospitals } \\
\text { to concentrate the prevention and treatment of rabies in a selected } \\
\text { center called the anti-rabies center of the town }\end{array}$ \\
\hline Personnel & $\begin{array}{l}\text { Lack of knowledge of rabies instructions on the part of the nurse, } \\
\text { lack of knowledge of rabies on the part of the specialist }\end{array}$ \\
\hline Program & $\begin{array}{l}\text { Poor planning to keep track of the affairs of the injured, lack of } \\
\text { planning in post-accident care }\end{array}$ \\
\hline
\end{tabular}

7-1-2 Descriptive statistics of the accident (death of a farmer as a result of attacking a rabid animal) In the first accident investigation, 23 experts of different staff units participated in completing the questionnaire. Frequency of different components including gender, age, working experience and academic degree of the subjects has been provided in the following.

\section{7-1-2-1 Frequency of the subjects' gender}

Table 3: Frequency of subjects in terms of gender

\begin{tabular}{|l|l|l|}
\hline Gender & Frequency & Percentage \\
\hline Female & 9 & 39.13 \\
\hline Male & 14 & 60.87 \\
\hline Total & 23 & 100 \\
\hline
\end{tabular}

According to Table 3, it is observed that 14 men $(60.87 \%)$ and 9 women $(39.13 \%)$ have participated in completing the first questionnaire on the event of animal bite.

Table 4: Frequency of subjects in terms of age

\begin{tabular}{|l|l|l|}
\hline Age & Frequency & Percentage \\
\hline $25-29$ & 1 & 4.35 \\
\hline $30-34$ & 1 & 4.35 \\
\hline $35-39$ & 8 & 34.78 \\
\hline $40-44$ & 2 & 8.70 \\
\hline $45-49$ & 10 & 43.48 \\
\hline$>50$ & 1 & 4.35 \\
\hline Total & 23 & 100 \\
\hline
\end{tabular}


Age frequency distribution of the experts who respond to the first questionnaire shows that $4.35 \%$ of the subjects were between 25 and 29 years; $4.35 \%$ were between 30 and 34 years; $34.78 \%$ were between 35 and 39 years; $8.70 \%$ were between 40 and 44 years; $43.48 \%$ were between 45 and 49 years which is the highest value among the respondents; and finally, $4.35 \%$ were over 50 years.
7-1-2-2 Frequency of subjects in terms of education

Frequency distribution of the subjects' educational level was as follows: $39.13 \%$ of the participants had a bachelor's degree; $47.83 \%$ had a master's degree; and $13.04 \%$ had a $\mathrm{PhD}$.

Table 5: Frequency of subjects in terms of education

\begin{tabular}{|l|l|l|}
\hline Educational level & Frequency & Percentage \\
\hline BA & 9 & 39.13 \\
\hline MA & 11 & 47.83 \\
\hline PhD & 3 & 13.04 \\
\hline Total & 23 & 100 \\
\hline
\end{tabular}

7-1-2-3 Frequency of subjects in terms of occupational experience

As can be seen in Table 5-3, 2.9\% of the participants had the working experience of less than 5 years, $31.4 \%$ had the working experience of 5 to 10 years, $31.4 \%$ had the working experience of 11 to 15 years, $14.4 \%$ had the working experience of 16 to 20 years, $5.7 \%$ had the working experience of 21 to 25 years and finally, $14.3 \%$ had the working experience of 26 to $30 \quad$ years

Table 6: Frequency of subjects in terms of working experience

\begin{tabular}{|l|l|l|}
\hline Working experience & Frequency & Percentage \\
\hline $5-9$ years & 2 & 8.70 \\
\hline $10-14$ years & 13 & 56.52 \\
\hline $15-19$ years & 5 & 21.74 \\
\hline $20-24$ years & 1 & 4.35 \\
\hline$>25$ & 2 & 8.70 \\
\hline Total & 23 & 100 \\
\hline
\end{tabular}

\section{7-1-3 Questionnaire reliability}

23 subjects who had responded to the questionnaire were analyzed. Cronbach's alpha of this questionnaire has been provided in Table 7.

Table 7: Reliability of the questionnaire on the accident (animal bite of the farmer)

\begin{tabular}{|l|l|l|}
\hline Variable name & Number of questions & Alpha value $(\alpha)$ \\
\hline Intermediate cause & 10 & \\
\hline Root cause control & 10 & \\
\cline { 1 - 1 } $\begin{array}{l}\text { Preventive and } \\
\text { measures }\end{array}$ & 10 & \\
\cline { 1 - 2 } Total & 30 & \\
\hline
\end{tabular}

Given the Table 7, the overall value of Cronbach's alpha is equal to .728 which indicates the acceptability of the reliability of the first questionnaire.

7-1-3 Inferential statistics of the accident 7-1-3-1 Kolmogorov-Smirnov test
To investigate the research hypotheses, it is necessary to examine the normality of variables considered in the questionnaires. Thus, this test is initially carried out. To determine the normality of data distribution in the first questionnaire and the related indicators or the intended variables that ultimately determine the research 
hypotheses, assumptions of Kolmogorov- Smirnov (K-S) test have been listed below.

Table 8: One-sample Kolmogorov-Smirnov test

\begin{tabular}{|l|l|l|}
\hline Variable & Questionnaire \\
\hline Number & 23 \\
\hline \multirow{2}{*}{$\begin{array}{l}\text { Parameters of normal } \\
\text { distribution }\end{array}$} & Mean & 3.398 \\
\cline { 2 - 3 } & SD & 0.805 \\
\cline { 2 - 3 } & Absolute value of differences & 0.174 \\
\hline \multirow{2}{*}{ Differences } & Positive value & 0.231 \\
\cline { 2 - 3 } & Negative value & -0.296 \\
\hline Kolmogorov-Smirnov statistic & .162 \\
\hline P-value (sig) & 0.001 \\
\hline
\end{tabular}

Considering the $\mathrm{P}$-value and comparing it with the significance level of $0.05(\mathrm{P}<0.05)$, it can be concluded that the assumption of normality of the variables in the first questionnaire is not accepted and in fact, it is rejected. According to the results of the above table, it is observed that the P-value is less that 0.05 and based on the interpretation of Kolmogorov-Smirnov test, distribution of these variables in the study is not normal. So, the subsequent analyses of the study should be made using authentic non-parametric tests. Accordingly, Kruskal-Wallis test was chosen as a desired test.

\section{7-1-3-2 Kruskal-Wallis test}

Table 9: Kruskal-Wallis test (intermediate causes)

\begin{tabular}{|l|l|l|l|l|l|}
\hline $\begin{array}{l}\text { Intermediate causes (unsafe acts and unsafe } \\
\text { conditions) }\end{array}$ & Mean & SD & $\begin{array}{l}\text { Minimum } \\
\text { score }\end{array}$ & $\begin{array}{l}\text { Maximum } \\
\text { score }\end{array}$ & Mean Rank \\
\hline $\begin{array}{l}\text { Innate fear of individuals when confronted } \\
\text { with animals }\end{array}$ & 2.869 & $868 /$ & 2 & 5 & 4.87 \\
\hline $\begin{array}{l}\text { Farmers' and ranchers unawareness of the } \\
\text { dangers of animals particularly the risk of } \\
\text { animal bite }\end{array}$ & 4.489 & $510 /$ & 4 & 5 & 7.42 \\
\hline Medical personnel's unawareness of rabies & 4.521 & $730 /$ & 3 & 5 & 7.54 \\
\hline $\begin{array}{l}\text { Negligence and inattentiveness when facing } \\
\text { animals }\end{array}$ & 3.391 & $782 /$ & 2 & 5 & 6.14 \\
\hline $\begin{array}{l}\text { Inattention to the environment where animals } \\
\text { traverse }\end{array}$ & 4.739 & $448 /$ & 4 & 3 & 7.26 \\
\hline $\begin{array}{l}\text { Courage and having a mood of defiance when } \\
\text { facing animals }\end{array}$ & 1.652 & $831 /$ & 2 & 4 & 4.94 \\
\hline $\begin{array}{l}\text { Lack of public awareness of the dangerous } \\
\text { diseases of domestic animals }\end{array}$ & 2.956 & $638 /$ & 2 & 5 & 4.93 \\
\hline $\begin{array}{l}\text { Unawareness of caring the vital organs while } \\
\text { conflicting with the aggressive animal }\end{array}$ & 4.913 & $288 /$ & 4 & 5 & 8.95 \\
\hline $\begin{array}{l}\text { Undue passage in the sites where dangerous } \\
\text { animals exist }\end{array}$ & 3.869 & $457 /$ & 3 & 5 & 6.29 \\
\hline $\begin{array}{l}\text { Unsafe exposure due to the occupational } \\
\text { nature (rancher, farmer, curator of the zoo, } \\
\text { veterinarian, ...) }\end{array}$ & 4.913 & $288 /$ & 4 & 5 & 8.97 \\
\hline $\begin{array}{l}\text { Intermediate causes } \\
6.63\end{array}$ & Kruskal-Wallis Test \\
\hline 9 & Df & & \\
\hline .036 & Asymp.sig \\
\hline
\end{tabular}


Considering the obtained sig which is equal to 0.036 , the assumption about the equality of distribution of observations in the studied groups is rejected. Given the P-value (0.036) obtained, the numerical value of intermediate causes is not the same and each of them alone can cause the occurrence of the mentioned accident.

\section{7-1-3-3 Root causes}

Table 10: Kruskal-Wallis test (root causes)

\begin{tabular}{|l|l|l|l|l|l|}
\hline Root causes & Mean & SD & $\begin{array}{l}\text { Minimum } \\
\text { score }\end{array}$ & $\begin{array}{l}\text { Maximum } \\
\text { score }\end{array}$ & Mean Rank \\
\hline $\begin{array}{l}\text { Lack of knowledge and } \\
\text { information on animals and } \\
\text { their diverse moods }\end{array}$ & 3.743 & .758 & 3 & 5 & 3.12 \\
\hline $\begin{array}{l}\text { Lack of knowledge of animal } \\
\text { bites and rabies and their } \\
\text { resulting dangers }\end{array}$ & 4.876 & $430 /$ & 4 & 5 & 7.42 \\
\hline $\begin{array}{l}\text { Lack of providing information } \\
\text { on animal bites by the health } \\
\text { centers }\end{array}$ & 4.323 & $467 /$ & 4 & 5 & 7.63 \\
\hline $\begin{array}{l}\text { Lack of providing information } \\
\text { on the dangers of animal bites } \\
\text { in broadcasting }\end{array}$ & 4.012 & 1.190 & 1 & 5 & 6.34 \\
\hline $\begin{array}{l}\text { Lack of giving information } \\
\text { concerning animal bites in } \\
\text { schools }\end{array}$ & 4.698 & $977 /$ & 1 & 4 & 6.90 \\
\hline $\begin{array}{l}\text { Lack of a regular and logical } \\
\text { program regarding the fight } \\
\text { against animal bites }\end{array}$ & 4.924 & 1.323 & 1 & 5 & 7.34 \\
\hline $\begin{array}{l}\text { Lack of proper supervision by } \\
\text { municipalities in dealing with } \\
\text { stray animals }\end{array}$ & 4.312 & $789 /$ & 2 & 5.93 \\
\hline $\begin{array}{l}\text { Lack of enjoying adequate } \\
\text { financial capacities to control } \\
\text { dangerous and stray animals }\end{array}$ & 3.967 & $213 /$ & 4 & 5 & 6.40 \\
\hline $\begin{array}{l}\text { Lack of a preventive program } \\
\text { through the concerned } \\
\text { authorities to fight against the } \\
\text { animal bite }\end{array}$ & 3.127 & $494 /$ & 3 & 5 & \\
\hline $\begin{array}{l}\text { Social apathy towards the } \\
\text { dangers of rabies and animal } \\
\text { bites }\end{array}$ & 2.134 & $221 /$ & 4 & 5 & \\
\hline
\end{tabular}

\begin{tabular}{|l|l|}
\hline Root causes & Kruskal-Wallis Test \\
\hline 7.21 & Chi-square \\
\hline 9 & Df \\
\hline .045 & Asymp.sig \\
\hline
\end{tabular}

Given the obtained sig which is equal to 0.045 , the assumption about the equality of distribution of observations in the studied groups is rejected. Considering the P-value (0.045) obtained, the numerical value of root causes is not the same and each of them alone can cause the occurrence of the mentioned accident. 


\section{7-1-3-4 Preventive and control measures}

Table 11: Kruskal-Wallis test (preventive and control measures)

\begin{tabular}{|c|c|c|c|c|c|}
\hline Root causes & Mean & SD & $\begin{array}{l}\text { Minimum } \\
\text { score }\end{array}$ & $\begin{array}{l}\text { Maximum } \\
\text { score }\end{array}$ & Mean Rank \\
\hline $\begin{array}{l}\text { Notification via broadcasting } \\
\text { and other social and mass } \\
\text { media }\end{array}$ & 4.743 & $558 /$ & 3 & 5 & 7.12 \\
\hline $\begin{array}{l}\text { Information supply in schools } \\
\text { about understanding rabies } \\
\text { and dangers of animal bites }\end{array}$ & 4.676 & $130 /$ & 4 & 5 & 6.93 \\
\hline $\begin{array}{l}\text { Information supply about } \\
\text { rabies and dangers of animal } \\
\text { bites by the health networks } \\
\text { of towns }\end{array}$ & 4.829 & $217 /$ & 4 & 5 & 8.24 \\
\hline $\begin{array}{l}\text { Allocation of separate and } \\
\text { considerable budget to deal } \\
\text { with and prevent animal } \\
\text { attacks in municipalities }\end{array}$ & 4.712 & 1.290 & 1 & 5 & 6.97 \\
\hline $\begin{array}{l}\text { Intersectoral collaboration } \\
\text { between health centers, } \\
\text { municipalities, police force, } \\
\ldots \text { regarding the prevention of } \\
\text { animal bites and their } \\
\text { consequences }\end{array}$ & 4.898 & $177 /$ & 4 & 5 & 9.02 \\
\hline $\begin{array}{l}\text { Training how to keep and } \\
\text { properly treat the domestic } \\
\text { animals }\end{array}$ & 2.924 & 1.523 & 1 & 5 & 3.87 \\
\hline $\begin{array}{l}\text { Attempt to strengthen } \\
\text { religious, social and cultural } \\
\text { beliefs in relation to keeping } \\
\text { animals or dealing with them } \\
\text { and the risks associated with } \\
\text { any animal }\end{array}$ & 3.312 & $776 /$ & 2 & 5 & 5.93 \\
\hline $\begin{array}{l}\text { Enlisting the aid of various } \\
\text { institutions especially } \\
\text { charitable and benevolent } \\
\text { institutions regarding the } \\
\text { prevention of animal bites }\end{array}$ & 2.967 & 1.301 & 1 & 5 & 4.42 \\
\hline $\begin{array}{l}\text { Preventive compiled and } \\
\text { integrated planning regarding } \\
\text { animal bites through the } \\
\text { relevant authorities }\end{array}$ & 4.827 & 494 & 3 & 5 & 7.95 \\
\hline $\begin{array}{l}\text { Developing or changing the } \\
\text { guidelines related to animal } \\
\text { bites }\end{array}$ & 1.134 & $421 /$ & 1 & 3 & 2.89 \\
\hline
\end{tabular}

\begin{tabular}{|l|l|}
\hline Preventive and control measures & Kruskal-Wallis Test \\
\hline 5.21 & Chi-square \\
\hline 9 & Df \\
\hline .005 & Asymp.sig \\
\hline
\end{tabular}


Given the obtained sig which is equal to 0.005 , the assumption about the equality of distribution of observations in the studied groups is rejected. Considering the P-value (0.005) obtained, the numerical value of preventive and control measures is not the same and each of them alone can prevent or control the occurrence of the mentioned accident.

\section{7-2 E \& CFA diagram relating to the accident}

Now, some questions arise:

\section{8- Discussion and conclusion}

\section{8-1 Discussion}

Totally, four similar studies with the subject of investigating the accidents using $\mathrm{E} \& \mathrm{CFA}$ method were observed by the researcher in Internet bases and different websites. Accordingly, results of each study are examined respectively.

1- According to the study by Clark and Buys (1995), E \& CFA method is an inseparable and important part of the risk assessment model of Management Oversight and Risk Tree (MORT) and often has a fundamental role in examining the accidents including industry events as the key to realizing the correct drawing of the risk tree by MORT method. Also, use of root cause-finding technique as the background of MORT method and synchronizing these two paths to determine the real and ultimate cause of errors and risks existing in the events occurred have favorable results especially in industry for energy tracking and analysis of risk factors. Based on this study, the most important factors associated with industry events particularly in relation to workers and also the events related to the workers of other occupations include unsafe acts and unsafe conditions whose main reason is the ignorance of the type of activity and its conditions. These results are consistent with the findings obtained
- Would this accident happen if this event had not occurred?

- How did this accident happen?

- What caused this accident?

In E \& CFA diagram (1), details of this accident have been investigated and primary and secondary succession, predisposing factors, chronology of the accident and the main and potential events and conditions have been shown.

from the accident of the present study. In this research, the root analysis method unlike the study of Clark and Buys was not completed and given an equivalent by MORT method.

2- By providing a practical guide and drawing a causal diagram to identify and analyze the risks existing in organizations with the general name of $\mathrm{HRO}_{\mathrm{S}}$ or high reliability in organizations, Hartley et al. (2008), while presenting checklists for examining the accidents and developing analytical forms to identify the causes of events, found that E \& CFA method as a prospective method can play an important role in preventing the occurrence of future events and pave the way for the comprehensive analysis of some events. In this research, considering the retrospective study of 13 events of the safe community project of Esfahan and then investigation of the selected accident, ultimately solutions to prevent the similar accidents were provided. The results were consistent with the findings obtained by Hartley et al. Generally, in this study, attempts have been made that the root model of cause and effect can introduce the following three solutions as the functions and features of the model, which had been mentioned in the study conducted by Hartley. These solutions are as follows: 
Figure 1: $\mathrm{E} \& \mathrm{CFA}$ diagram relating to the accident
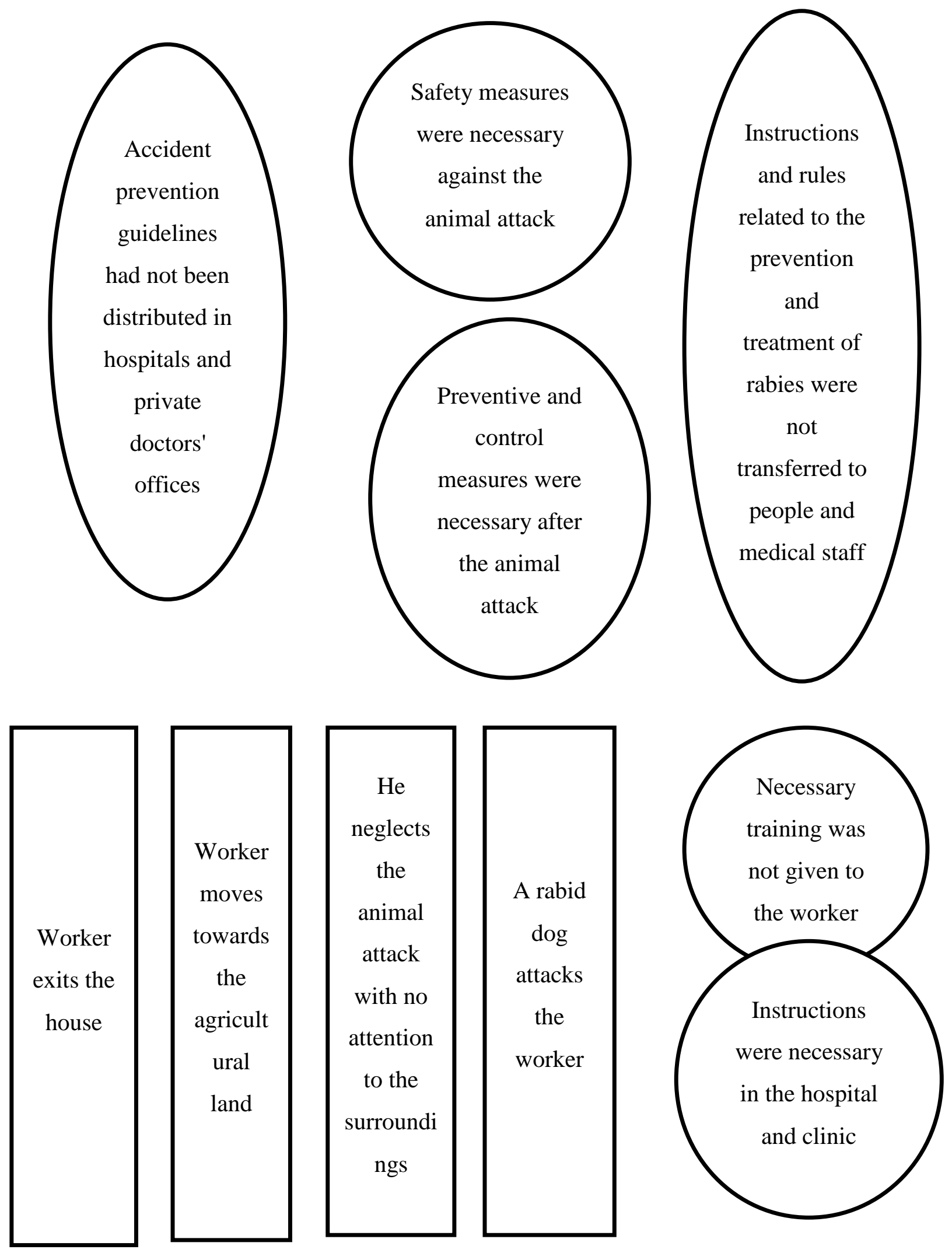


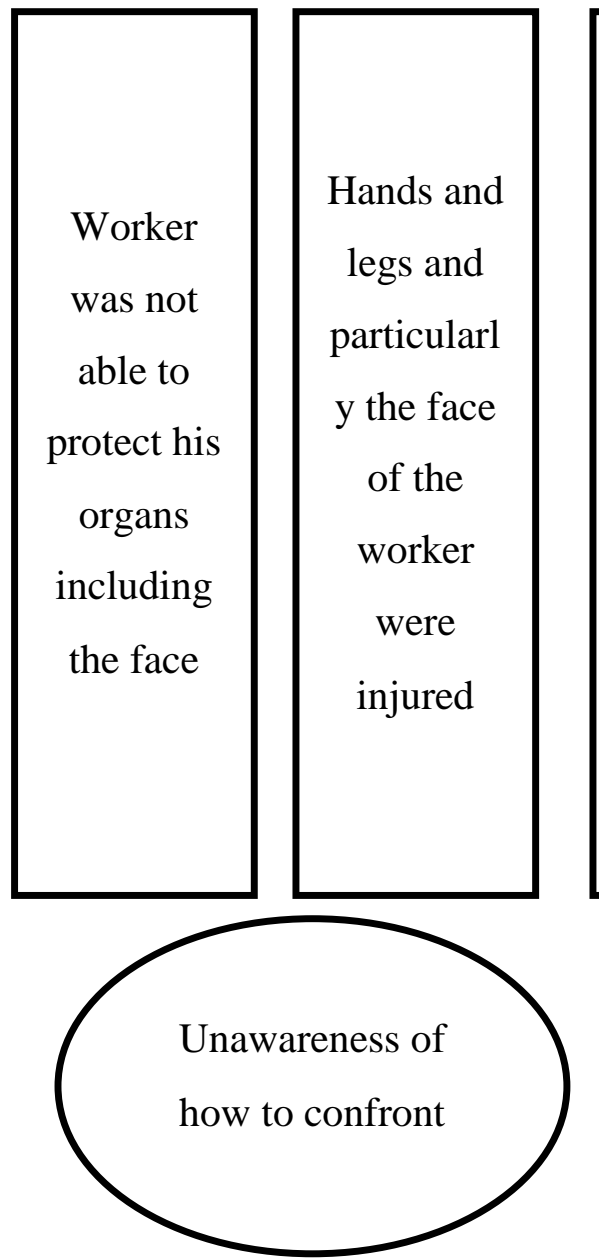

1) Prevention of recurrent events;

2) Prevention of similar accidents;

3) Enhancing the reliability of the system and organization.

Besides, in this research like the study of Hartley et al., the diagrams related to root cause-finding methods were drawn and two common and important tools of 5-why and Ishikawa diagram were used.

3- In other studies such as the research conducted by Jackson and Priestley (2001), generally several methods of risk assessment under the title of a systematic review of the root causes of accidents were applied which include MORT model and other analysis methods of events. Finally, it was concluded that none of the risk assessment models can fully identify and analyze the events in question. Then, advantages and disadvantages of the causal and MORT models and the results of using each of them were discussed. In this study, all the methods

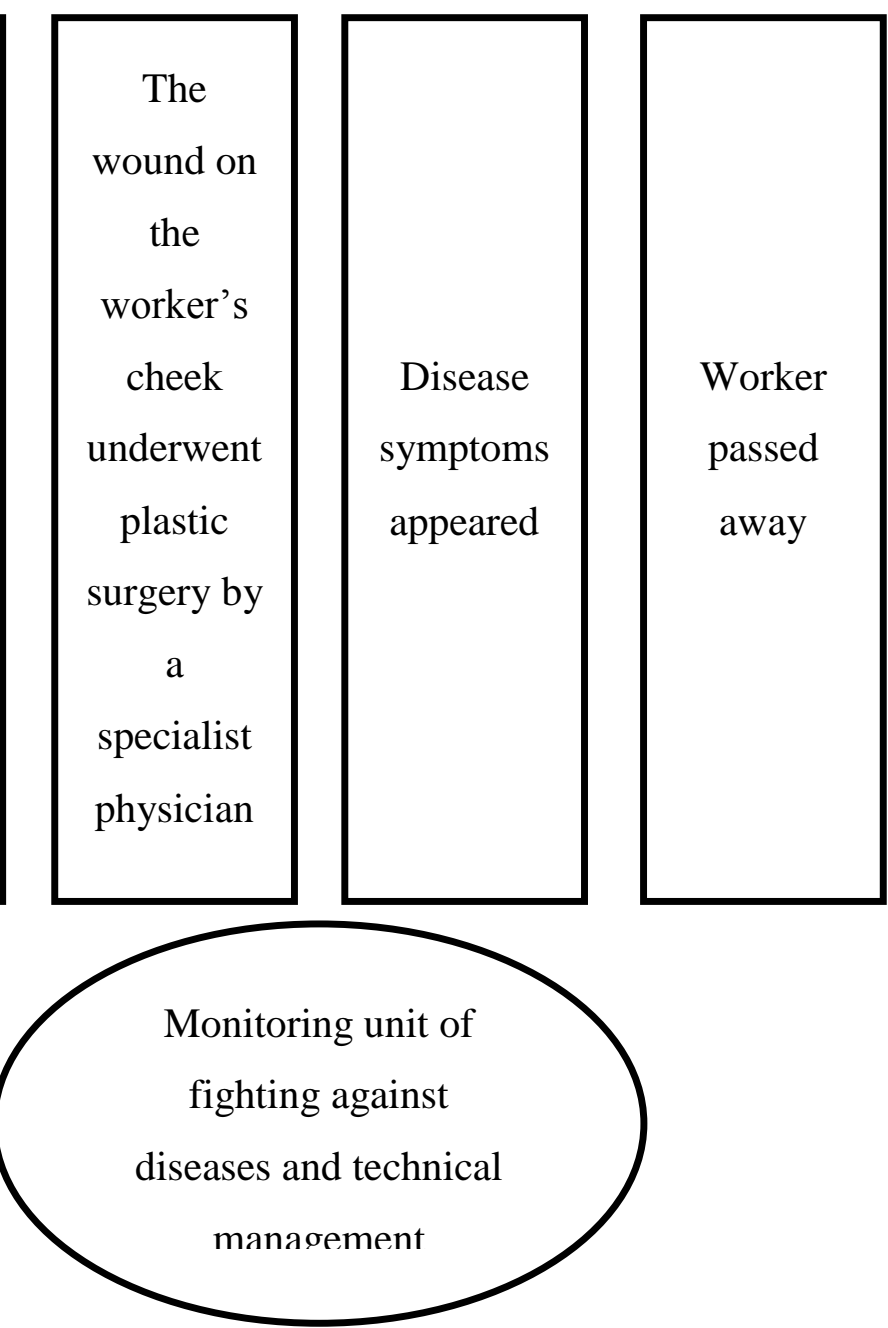

associated with cause-finding in accidents were introduced in detail and the advantages and disadvantages of each were explained. In addition, epidemiological methods of root causefinding were emphasized.

4- In this research like the study carried out by Akbari Ajbisheh (2013)_ who in her thesis entitled "Analysis of the events of the automotive industry" examined the events related to Bahman Automotive Group on a case-by-case basis using E \& CFA method_events of the safe community project were fully investigated in terms of frequency and year and finally, similar to the study of Ms. Akbari, the two selected accidents were analyzed using E \& CFA method and the diagram of each was drawn. Unlike the study of Akbari in which one-sample $t$ test results were applied to investigate the importance of the intermediate causes of events, only KruskalWallis test was used in this study and to rank the intermediate and root causes, only results of 


\section{Zarei1 et al}

ranking the subjects which was in the form of the average of each component were used whereas in the aforementioned study, Friedman test was employed for the ranking of the components.

In the research performed by Tahmasbi (2013) entitled "Analyzing the causes of accidents resulting from working in the construction sites of mass housing projects using SCAT method: Case study of Qom", nonparametric tests of Kruskal-Wallis and Wilcoxon were used. In the present article, only Wilcoxon test was applied to examine the importance of each component or factor in the occurrence of the accident and rank the causes.

\section{8-2 Conclusion}

\section{8-2-1 Investigation of intermediate causes}

Given the obtained sig (0.036) in the event of the rabid animal attack on the farmer, the assumption about the equality of distribution of observations in the studied groups is rejected. Considering the P-value (0.036) obtained, the numerical value of intermediate causes is not the same and each of them alone can cause the occurrence of the mentioned accident.

\section{8-2-2 Investigation of root causes}

By performing the Kruskal-Wallis test regarding the root causes of the accident and given the obtained sig (0.045), the assumption about the equality of distribution of observations in the studied groups is rejected. Considering the Pvalue (0.045) obtained, the numerical value of root causes is not the same and each of them alone can cause the occurrence of the mentioned accident.

\section{8-2-3 Investigation of preventive and control measures}

By conducting the Kruskal-Wallis test in the accident and given the obtained sig (0.005), the assumption about the equality of distribution of observations in the studied groups is rejected. Considering the P-value (0.005) obtained, the numerical value of preventive and control measures is not the same and each of them alone can prevent or control the occurrence of the mentioned accident.

\section{8-2-4 Answering the research questions}

Considering the results of the tests related to the analyzed accident, the research questions will be answered as follows:
First question: What is the direct cause of the occurrence of accidents leading to death or severe injury with regard to the program of country event registration in Esfahan Province?

The first principle of the safe community states that the direct cause of each accident is the failure to adhere to the principles set forth in this plan and includes the intermediate causes of accidents such as unsafe acts and unsafe conditions and root causes such as negligence in management and supervision and lack of planning and proper and timely application of various aid sources including financial resources and social and cultural factors (Gelen, 1944). Hence, if we consider the direct cause of the accidents leading to death mentioned above and fully examine the selected accident including the animal attack, we see that the basic principles written in the safe community have not been observed in it and the obtained intermediate and root causes answer the first research question.

Second question: What are the intermediate causes of the occurrence of accidents leading to death or severe injury with regard to the program of country event registration in Esfahan Province?

Concerning the event of the rabid animal attack on the farmer, intermediate causes consisted of inattention, ignorance, distraction and unfamiliarity. According to the country project of the safe community, the most important intermediate cause in accidents includes recklessness, human errors and negligence in the application of safety principles.

Description of intermediate causes as a result of which the event of the rabid animal attack occurred has been provided in Table 12 .

Third question: What are the root causes of the occurrence of accidents leading to death or severe injury with regard to the program of country event registration in Esfahan Province?

Based on the program of country event registration in Esfahan, the most important root cause in accidents includes the lack of proper training and non-adherence to safety principles of the safe community project. In order to answer the third question and examine the abovementioned hypothesis, the root causes of both accidents have been presented together in Table 13. 
Table 12: Intermediate causes in the occurrence of the accident of the rabid animal attack on the farmer

\begin{tabular}{|l|l|}
\hline No. & Intermediate causes in the accident (rabid animal attack on the farmer) \\
\hline 1 & $\begin{array}{l}\text { Unsafe exposure due to the occupational nature (rancher, farmer, curator of the zoo, } \\
\text { veterinarian,...) }\end{array}$ \\
\hline 2 & Unawareness of the vital organs care while conflicting with the aggressive animal \\
\hline 3 & Unawareness of rabies \\
\hline 4 & Unawareness of the risks of animals especially the risk of animal bites \\
\hline 5 & Inattention to the environment where animals traverse \\
\hline 6 & Undue passage in the sites where dangerous animals exist \\
\hline 7 & Negligence and inattention when faced with animals \\
\hline 8 & Innate fear when confronted with animals \\
\hline 9 & Courage and having a mood of defiance when facing animals \\
\hline 10 & Lack of knowledge and information about animals and their diverse moods \\
\hline
\end{tabular}

Table 13: Root causes in the occurrence of the accident

\begin{tabular}{|l|l|}
\hline No & Root causes in the accident (rabid animal attack on the farmer) \\
\hline 1 & Social apathy towards the dangers of rabies and animal bites \\
\hline 2 & Lack of a regular and logical program regarding the fight against animal bites \\
\hline 3 & Lack of a preventive program through relevant authorities to deal with animal bites \\
\hline 4 & Lack of proper supervision by municipalities in dealing with stray animals \\
\hline 5 & Lack of notification about animal bites by health centers \\
\hline 6 & Lack of knowledge regarding animal bites and rabies and their resulting dangers \\
\hline 7 & Lack of notification about animal bites in schools \\
\hline 8 & Lack of benefiting from financial capacities to control dangerous and stray animals \\
\hline 9 & Lack of notification about the dangers of animal bites in broadcasting \\
\hline 10 & Lack of knowledge and information about animals and their divers moods \\
\hline
\end{tabular}

Table 14: Comparing the suggested solutions in the event of animal attack

\begin{tabular}{|l|l|}
\hline No & Preventive and control solutions in the accident (rabid animal attack on the farmer) \\
\hline 1 & $\begin{array}{l}\text { Intersectoral collaboration between health centers municinalities nolice force } \\
\text { the prevention of animal bit } \quad \text { Zareil } \text { et al }\end{array}$ \\
\hline 2 & Notification about rabies and dangers of animal bites by the health networks of towns \\
\hline 3 & $\begin{array}{l}\text { Preventive compiled and integrated planning regarding animal bites through the relevant } \\
\text { authorities }\end{array}$ \\
\hline 4 & Notification via broadcasting and other social and mass media \\
\hline 5 & $\begin{array}{l}\text { Allocation of separate and considerable budget to deal with and prevent animal attacks in } \\
\text { municipalities }\end{array}$ \\
\hline 6 & Notification in schools about the understanding of rabies and dangers of animal bites \\
\hline 7 & $\begin{array}{l}\text { Attempt to strengthen religious, social and cultural beliefs regarding keeping animals or } \\
\text { dealing with them and the risks associated with any animal }\end{array}$ \\
\hline 8 & $\begin{array}{l}\text { Enlisting the aid of various institutions especially charitable and benevolent institutions } \\
\text { regarding the prevention of animal bites }\end{array}$ \\
\hline 9 & Training how to keep and properly deal with domestic animals \\
\hline 10 & Developing or changing the guidelines related to animal bites \\
\hline
\end{tabular}




\section{Zarei1 et al}

As can be observed, the obvious and specific root cause in the accident is the lack of necessary training concerning the prevention and control of these events. But principles of the safe community in preventing the occurrence of the accidents in the section of root causes include improper or inadequate supervision or lack of supervision, improper management or mismanagement of executive officials, lack of benefiting from various capacities such as political, cultural and financial capacities, absence of guidelines or manuals or data references and weakness or lack of using such resources (Gelen, 1944). This indicates that all of these root causes considered by the safe community project of Esfahan have been properly observed and investigated in this study.

8-2-5 Preventive and control strategies according to the results of the research questionnaires

In Table 14, while comparing the suggested solutions obtained from the comments of thesubjects, it can be noted that planning and training, intersectoral collaboration and use of various social and economic capacities can form a great volume of preventive and control solutions.

\section{References}

Haji Hoseini, A. 2010. Human error engineering. Tehran: Fanavaran Publications.

HSE engineering website (Health, Safety and Environment). 2013. Introducing various models of risk assessment. Tehran.

Mohammadfam, I. 2011. Safety engineering of the techniques to identify, assess and control the risks in industrial environments. Tehran: Fanavaran Publications.

Gelen, V. 1994. A guide for the safe community, an introduction to the promotion of safety. Translated by Sh. Rafieifar et al. Tehran, Ministry of Health and Medical Education, Department of Health, Center for Disease Control. 